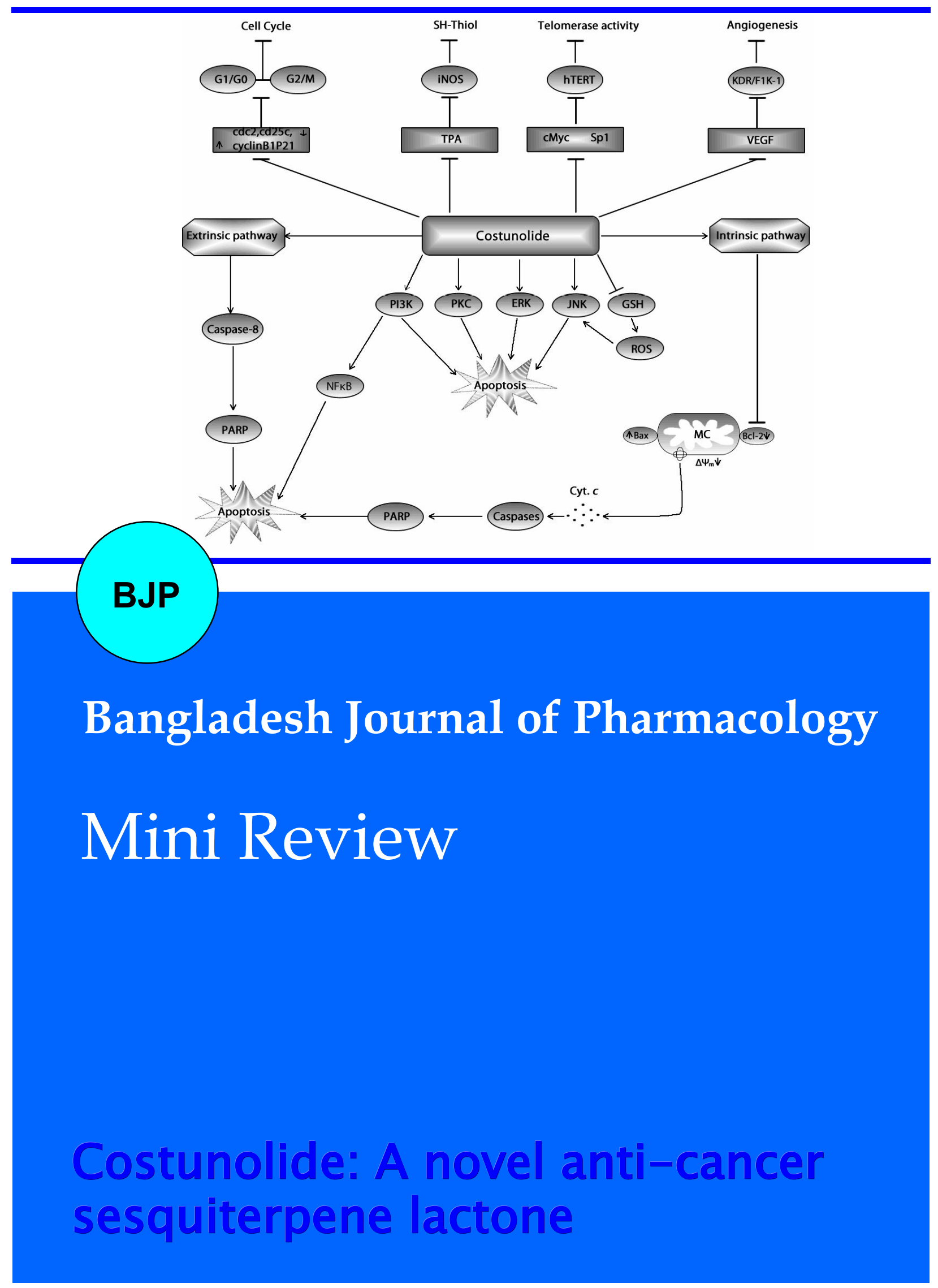


Abstracted/indexed in Academic Search Complete, Asia Journals Online, Bangladesh Journals Online, Biological Abstracts, BIOSIS Previews, CAB Abstracts, Current Abstracts, Directory of Open Access Journals, EMBASE/Excerpta Medica, Google Scholar, HINARI (WHO), International Pharmaceutical Abstracts, Open J-gate, Science Citation Index Expanded, SCOPUS and Social Sciences Citation Index;

ISSN: $1991-0088$

\title{
Costunolide: A novel anti-cancer sesquiterpene lactone
}

\author{
Azhar Rasul' ${ }^{1}$, Saima Parveen² and Tonghui Ma1
}

${ }^{1}$ Central Research Laboratory, Jilin University Bethune Second Hospital, Changchun, 130 041, P. R. China; ${ }^{2}$ Department of Chemistry, Faculty of Science, The Islamia University of Bahawalpur, 63 100, Pakistan.

\begin{tabular}{|c|c|}
\hline Article Info & \\
\hline Received: & 8 March 2012 \\
\hline Accepted: & 9 March 2012 \\
\hline Available Online: & 11 March 2012 \\
\hline DOI: $10.3329 /$ bjp. & .10066 \\
\hline $\begin{array}{l}\text { Cite this article: } \\
\text { Rasul A, Par } \\
\text { Costunolide: A } \\
\text { sesquiterpene lac } \\
\text { Pharmacol. 2012; } 7\end{array}$ & $\begin{array}{l}\text { S, Ma T. } \\
\text { vel anti-cancer } \\
\text { 13. Bangladesh J }\end{array}$ \\
\hline
\end{tabular}

\begin{abstract}
Currently an ample interest is found among oncologists to explore anti-cancer compounds from herbs. Sesquiterpene lactones have accredited significant attention in pharmacological research. Costunolide is a well-known sesquiterpene lactone present in plants used as popular herbal remedy. Several plantderived compounds are currently successfully employed in cancer treatment. Growing evidences demonstrated that costunolide possesses anti-cancer activities by inhibiting cell proliferation, tumor invasion, angiogenesis, metastasis and inducing apoptosis of a variety of tumor cell lines. This review is aimed to summarize the recent researches about costunolide focusing on anti-tumor activity and to lay emphasis on its molecular targets and its mechanisms, which may help the further design and conduct of preclinical and clinical trials.
\end{abstract}

\section{Introduction}

Cancer is the leading cause of death and represents one of the most threatening diseases worldwide. In the recent report, it has been estimated that 12.7 million new cancer cases and 7.6 million cancer deaths occur in 2008 , with $56 \%$ of new cancer cases and $63 \%$ of the cancer deaths occurring in the less developed regions of the world (Ferlay et al., 2010). Throughout the history of civilization, the human have relied on natural products as a primary source of medicine. Herbal medicines have been proven to be an important source of novel agents with a pharmaceutical potential. Many anti-cancer drugs in current use are either natural products or are derived from natural products. Herbal medicines, such as paclitaxel, camptothecin, vinca alkaloids, and etoposide hold great potential as promising agents for the treatment of cancer (Cragg and Newman, 2005). Natural products have tradition-ally provided a rich source of drugs for many diseases, including cancer and plants are an important source of novel natural products (Amin et al., 2009). In 2008, of the 225 drugs being developed, 164 were of natural origin, with 108 being derived from plants, 25 from bacterial sources, 7 from fungal and 24 from animal sources. And, to throw some more numbers around, of the 108 plant-based drugs, 46 were in preclinical development, 14 in phase I, 41 in phase II, 5 in phase III and two had already reached pre-registration stage (Harvey, 2008). David Newman and Gordon Cragg (Newman and Cragg, 2007) found that of 155 FDA-approved small molecule anti-cancer drugs, $47 \%$ were either natural products or directly derived there from.

Costunolide (6E,10E,11aR)-6,10-dimethyl-3methylidene-3a,4,5,8,9,11a-hexahydrocyclodeca [b] furan-2-one) is a sesquiterpene lactone. It is a colorless crystalline powder with molecular formula of $\mathrm{C}_{15} \mathrm{H}_{20} \mathrm{O}_{2}$ and molecular weight of $232.318 \mathrm{~g} / \mathrm{mol}$ (Figure 1). This review is aimed to summarize the recent researches on costunolide focusing on anti-cancer activity and to lay emphasis on molecular mechanisms which suggests a promising for such pursuits in oncology. Literature was searched through Pub Med, Scopus and Elsevier Science Direct Journal. Access to the Elsevier Science

Direct Journal was made possible through library of 


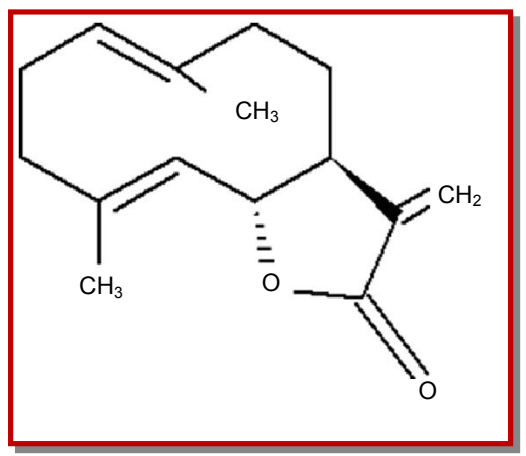

Figure 1: Structure of costunolide

Northeast Normal University. Throughout our literature search we mainly focused on recent studies. Additional manual searches were carried out on relevant medical journals and the Google Search Engine. Key words used for search were "costunolide", "anticancer mechanism", "Traditional Chinese medicine", "cancer therapy", and "cytotoxicity". No restrictions were levied on the language of publication. Only primary data or data that superseded earlier work were included.

Accumulated data indicate that Costunolide was isolated from many plant species such as Saussurea lappa (Lee et al., 2001; Li et al., 2006; Zhang et al., 2011), Aucklandia lappa Decne (Li et al., 2005; Rasul et al., 2011), Michelia floribunda (Mondranondra et al., 1990), Magnolia grandiflora (el-Feraly and Chan, 1978; Wu et al., 2001), Podachaenium eminens (Castro et al., 2000), Magnolia sieboldii (Park et al., 2001a; Park et al., 2001b), Tsoongiodendron odorum Chun (Song et al., 2001), Cosmos pringlei (Mata et al., 2002), Laurus nobilis (De Marino et al., 2005; Matsuda et al., 2002), Laurus novocanariensis (Ferrari et al., 2005), Magnolia kobus (Park et al., 2010), Eupatorium lindleyanum (Yang et al., 2010), and Magnolia ovata (Kassuya et al., 2009).

\section{Biological Functions}

As a medicine, costunolide is a famous sesquiterpene lactone, which is used as popular herbal remedies, with anti-ulcer (Matsuda et al., 2002; Pandey et al., 2007), anti -inflammatory (Kassuya et al., 2009; Macias et al., 1999; Mondranondra et al., 1990; Pae et al., 2007; Park et al., 1996; Song et al., 2001; Stefani et al., 2006), anti-fungal (Barrero et al., 2000; Kang et al., 2004; Wedge et al., 2000), anti-viral properties (Chen et al., 1995), Antipyretic (Kassuya et al., 2009), antimycobacterial activities (Fischer et al., 1998; Luna-Herrera et al., 2007), and inhibition of the cellular production of melanin (Choi et al., 2008), human lamin-B by farnesyl-protein transferase (FPTase) (Park et al., 2001b), and protein tyrosine phosphatase 1B (hPTP1B) (Li et al., 2006). Costunolide exhibited strong larvicidal activity against A. albopictus (Liu et al., 2011b). It also reported that, costunolide is involved to inhibit the expression of inducible nitric oxide synthase (De Marino et al., 2005; Fukuda et al., 2001; Matsuda et al., 2000; Park et al., 1996) and the DNA-binding activity of NF-KB (Castro et al., 2000; Koo et al., 2001; Stefani et al., 2006) and has potential as natural herbicide (Macias et al., 1999). Furthermore, costunolide potentiated 1,25-(OH)2D3induced differentiation in HL-60 promyelocytic leukemia cells (Choi et al., 2002b; Kim et al., 2008; Kim et al., 2002), via the interference with NF-kB activation. Further studies demonstrate that costunolide has antitumor potential by inhibiting proliferation, inducing apoptosis and reducing invasion and metastasis of a wide variety of tumor cells, including breast cancer cells (Bocca et al., 2004; Choi et al., 2005; Choi et al., 2011), hepatocellular carcinoma cells (Chen et al., 1995; Liu et al., 2011a; Sun et al., 2003), prostate cancer cells (Hsu et al., 2011), leukemia cells (Choi et al., 2002a; Choi and Lee, 2009; Choi et al., 2002b; Hibasami et al., 2003; Kanno et al., 2008; Kim et al., 2008; Kim et al., 2002; Kim et al., 2011b; Komiya et al., 2004; Lee et al., 2001; Song et al., 2001; Srivastava et al., 2006), gastric cancer cells (Ko et al., 2005; Rasul et al., 2011), colon cancer cells (Kawamori et al., 1995; Mori et al., 1994), melanoma cells (Chen et al., 2007; Park et al., 2001b), cervical cancer cells (Sun et al., 2003), KB and P388 tumor cell (Mondranondra et al., 1990), and platinum-resistant human ovarian cancer cells (Yang et al., 2011). It was also reported that costunolide inhibited angiogenic response by blocking the angiogenic factor signaling pathway (Jeong et al., 2002) and microtubule-interactting activity of costunolide (Bocca et al., 2004).

\section{Mechanism of Anti-cancer Activity}

Accumulated data indicate that, costunolide has potent anti-cancer activity, although several studies have conducted to determine the mechanism of anti-cancer activity of costunolide against variety of cancer cells. Yet mechanism of cytotoxic activity of costunolide has not been fully elucidated. Here, we reviewed studies related to anti-cancer activity of costunolide till now and have summarized the as yet reported pathways (Figure 2).

\section{Effects on Apoptosis}

Apoptosis is an evolutionally conserved process of cell death mediated by the activation of specific proteases, the caspases, and characterized by DNA fragmentation and nuclear condensation (Kroemer et al., 1995). The induction of apoptosis in tumor cells is an important mechanism for the efficiency of chemotherapy drugs. It has been reported that some kinds of sesquiterpene compounds induced apoptosis in cancer cells (Furuya et al., 1994; Woynarowski et al., 1997) and costunolide 


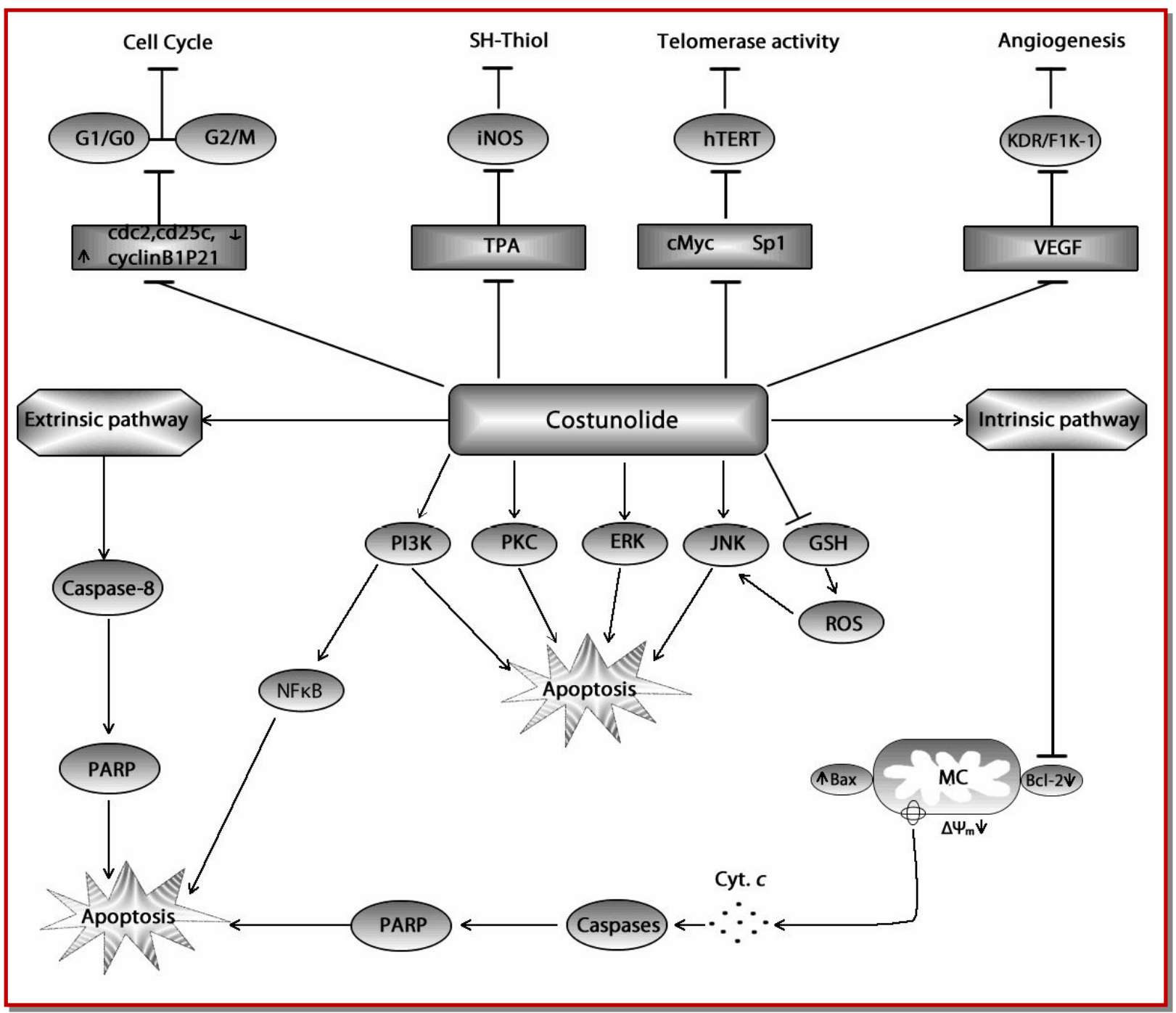

Figure 2: Schematic representation of the molecular mechanisms for the anti-cancer activity of costunolide

was also proven to have preventive effects on intestinal carcinogenesis, (Mori et al., 1994) suggesting an apoptosis-inducing activity of costunolide. Studies demonstrate that costunolide induces apoptosis in HL60 human leukemia cells by the ROS-mediated mitochondrial permeability transition and resultant cytochrome c release (Lee et al., 2001), activates the cleavage of poly-(ADP-ribose) polymerase (Park et al., 2001a), by depleting intracellular thiols (Choi et al., 2002a) and inducing the chromatin condensation (Hibasami et al., 2003; Komiya et al., 2004). Costunolide -induced apoptotic mechanisms are that the receptormediated pathway precedes the mitochondriadependent pathway, caused by the inhibition of telomerase activity via suppression of hTERT in NALM6 cells (Kanno et al., 2008), alters the balance of antiapoptotic Bcl-2 (Choi et al., 2002a; Rasul et al., 2011) and induces apoptosis by activation of c-Jun N-terminal kinase (JNK) in leukemic U937 cells (Choi and Lee,
2009) and inhibition of the prosurvival Akt and nuclear factor kappa B signaling pathway in human endometriotic epithelial cells (Kim et al., 2011a). Furthermore, costunolide induces the depletion of intracellular thiols and overload of nuclear $\mathrm{Ca}^{2+}$, and inhibits $\mathrm{Rb}$ phosphorylation in prostrate cancer cells (Hsu et al., 2011) and Fas-mediated extrinsic apoptosis in estrogen receptor-negative breast cancer cells, MDAMB-231cells (Choi et al., 2011).

\section{Effects on cell proliferation and cell cycle}

Evidence shows that costunolide reduces tumor development by inhibiting cancer cell proliferation and altering cell cycle. Studies comparing a number of sesquiterpene compounds show that costunolide inhibits the proliferation of human cancer cell lines representative of hepatocellular carcinoma (HCC) cells (Liu et al., 2011a), prostate cancer (Hsu et al., 2011), gastric cancer cells (Rasul et al., 2011), and estrogen 


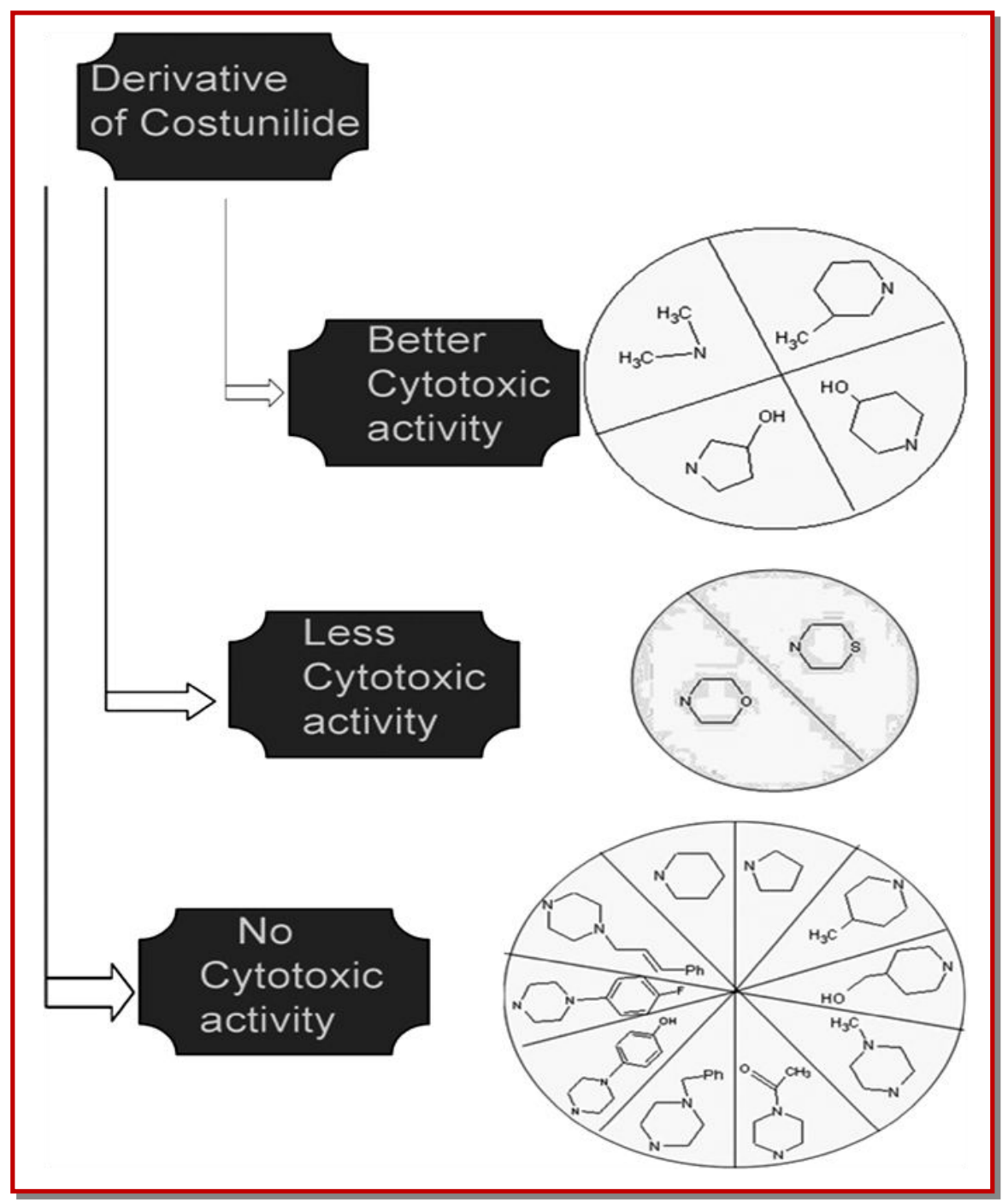

Figure 3: Illustrating the relationship between the structure and anti-cancer activity of costunolide

receptor-negative breast cancer cells, MDA-MB-23 (Choi et al., 2011). Moreover, Saussurea lappa fraction containing the costunolide arrested cell cycle at G2/M phase in AGS gastric cancer cells (Ko et al., 2005). Now it is clear that anti-proliferative effects involve the arrest of cell cycle progression. Accumulated data indicated that costunolide arrested the cell cycle in different phases in a cell line dependent manner such as in gastric cancer and breast cancer cells, MDA-MB-23 at G2/M Phase (Choi and Lee, 2009; Ko et al., 2005; Rasul et al., 2011), in hepatocellular carcinoma (HCC) cells at mitosis, not G2 phase, and in prostate cancer at G1 phase. The cell cycle progression is controlled by activation and inactivation of different classes of cyclins, cyclin-dependent kinase (Cdk) and other regulatory proteins. Among them, the activated cdc2/ cyclinB regulates the cell cycle progression from G2 to M phase (Taylor and Stark, 2001). The cyclin-dependent kinase inhibitor p21 (also known as p21WAF1/Cip1) promotes cell cycle arrest in response to many stimuli
(Abbas and Dutta, 2009). In both androgen-dependent (LNCaP) and independent (PC-3 and DU-145) prostate cancer cells, costunolide arrests the cell cycle at G1 phase which involve the association of p21 with the cyclin dependent kinase 2/cyclin E complex blocks cyclin dependent kinase 2 activity and inhibits $\mathrm{Rb}$ phosphorylation (Hsu et al., 2011). Furthermore, costunolide induced cell cycle arrest in the G2/M phase via decrease in $\mathrm{Cdc} 2$, cyclin $\mathrm{B} 1$ and increase in p21WAF1 expression, independent of p53 pathway in p53-mutant MDA-MB-231 cells and increases Cdc2p21WAF1 binding (Choi et al., 2011).

\section{Effects on Angiogenesis}

Angiogenesis is the generation and growth of new blood vessels from pre-existing vessels. When the balance between angiogenic and angiostatic factors is disrupted, tumor cells may begin to release uncon- 
trolled angiogenic factors, including vascular endothelial growth factor (VEGF) and basic fibroblast growth factor (bFGF) (Liekens et al., 2001). These factors go on to stimulate endothelial cell proliferation, and newly formed endothelial cells break down the extracellular matrix, migrate to cancer cells, and eventually begin to form lumen. Tumor angiogenesis is well known to play a key role in tumor growth and metastasis (Hoeben et al., 2004; Liekens et al., 2001), and angiogenesis inhibitors have been regarded as potential therapeutic agents for cancer treatment (Griffioen and Molema, 2000). Jeong et al has been reported that costunolide inhibits human umbilical vein endothelial cells (HUVECs) prolifiration and migration by blocking the angiogenic factor signaling pathway and inhibited the VEGF-induced autophosphorylation of KDR/ Flk-1 in NIH 3T3 cells overexpressing KDR/Flk-1 which is related with endothelial cells angiogenesis. Moreover, an in vivo mouse corneal micropocket assay, angiogenesis model has further confirmed that costunolide suppressed VEGF-induced neovascularization in mouse cornea. Taken together, these results suggested that costunolide is a potent angiogenesis inhibitor with the potential to be adopted as a novel agent in anti-cancer therapy (Jeong et al., 2002).

\section{Other Effects}

Costunolide reduced four azoxymethane-induced biomarkers, such as the frequencies of $\mathrm{ACF} /$ colon, ornithine decarboxylase activity, polyamine concentration level, and silver-stained nucleolar organizer region number in the colon and azoxymethane-induced intestinal carcinogenesis in rats which provide the evidence that costunolide could be a promising chemopreventive agent for human colon and intestinal neoplasia (Kawamori et al., 1995; Mori et al., 1994). Oxidative stress and inflammatory disorders are now widely known as a major pathogenetic factor of carcinogenic malignant transformation. In HL-60 human leukemia cells, costunolide has been shown to induce oxidative stress and cause subsequent apoptosis by elevating intracellular ROS and nitric oxide levels and reducing cellular anti-oxidant capacity (Lee et al., 2001). The nuclear factor-kappa B (NF-kB) belongs to the transcription factors family and plays a critical role in several signal transduction pathways involved in various cancers. Activation of NF- $\mathrm{KB}$ is involved in proliferation, invasion and apoptosis of tumor cells, either promoting or inhibiting, depending on cell type and condition (Nam, 2006). Costunolide inhibits the telomerase activity by down regulation of hTERT and transcriptional factors c-Myc and SP1 (Choi et al., 2005), whereas costunolide inhibits NF- $\mathrm{kB}$ activation and iNOS induction (Fukuda et al., 2001; Matsuda et al., 2000). Koo et al. showed that costunolide also dose dependently inhibited LPS-induced NF-кB activation
(Koo et al., 2001).

\section{Structure Activity Relationship}

It is generally believed that the bioactivity of sesquiterpene lactone is mediated by alkylation of nucleophiles through their $\alpha, \beta$ - or $\alpha, \beta$, $\gamma$-unsaturated carbonyl structures, such as $\alpha$-methylene- $\gamma$-lactones or $\alpha, \beta$ unsaturated cyclopentenones. These structure elements react with nucleophiles, especially the cysteine sulfhydryl groups by Michael-type addition. Therefore, it is widely accepted that thiol groups such as cysteine residues in proteins, as well as the free intracellular GSH, serve as the major targets of sesquiterpene lactone. In essence, the interaction between sesquiterpene lactone and protein thiol groups or GSH leads to reduction of enzyme activity or causes the disruption of GSH metabolism and vitally important intracellular cell redox balance. Sesquiterpines having exo-methylene group on lactone part are responsible for cytotoxic activity. The relationship between chemical structure and bioactivity of costunolide has been studied in several systems, especially with regards to cytotoxicity. It has been reported that exo-methylene group on lactone part of sesquiterpene lactones is required for eliciting cytotoxicity (Sun et al., 2003; Zhang et al., 2005). It (Srivastava et al., 2006) has been reported that costunolide having exo-methylene group exhibits good activity, when exo-double bond on position 13 was replaced with methoxy group and C-4 double bond was substituted with carbonyl, cytotoxicity decreased drastically against Colo205, A431, MCF-7 and A549 cell lines (Figure 3). The compound, costunolide showed little effect on the viability of human hepatoma Hep3B cells when observed in Hep3B and HepA2, but it lowered down the rate of production of hepatitis $B$ surface antigen (HBsAg) and hepatitis B e antigen (HBeAg) in a dose-dependent manner with $\mathrm{IC}_{50 \mathrm{~S}}$ of 1.0 and $2.0 \mu \mathrm{M}$. The suppression process occurred at mRNA level which was found through Northern blotting analysis. (Chen et al., 1995; Corona et al., 2005).

\section{Conclusion and Future Perspectives}

The studies described in this review show that the antitumor capacity of costunolide is due to inhibition of proliferation, invasion and metastasis, as well as induction of apoptosis, indicating that costunolide has the potential to become an effective, systemic antitumor remedy. However, the safety, tolerance and pharmacokinetics of costunolide have not been fully tested on either animals or humans. There is need to conduct studies to test the acute toxicity of costunolide on animals or humans, providing a rationale for clinical development of costunolide as a novel remedy in cancer therapy. Unfortunately, to date, no attempts 
have yet been made to test the chemotherapeutic potential and safety of costunolide at the preclinical and clinical level. The major challenges in the future are the development of an appropriate dosage form and the evaluation of clinical study employing costunolide.

\section{Acknowledgement}

This work has been supported by Ministry of Education of Pakistan and China Scholarship Council of China for doctoral degree. The authors would like to acknowledge Muhammad Rauf for editing of figures.

\section{References}

Abbas T, Dutta A. p21 in cancer: Intricate networks and multiple activities. Nat Rev Cancer. 2009; 9: 400-14.

Amin AR, Kucuk O, Khuri FR, Shin DM. Perspectives for cancer prevention with natural compounds. J Clin Oncol. 2009; 27: 2712-25.

Barrero AF, Oltra JE, Alvarez M, Raslan DS, Saude DA, Akssira M. New sources and antifungal activity of sesquiterpene lactones. Fitoterapia 2000; 71: 60-64.

Bocca C, Gabriel L, Bozzo F, Miglietta A. A sesquiterpene lactone, costunolide, interacts with microtubule protein and inhibits the growth of MCF-7 cells. Chem Biol Interact. 2004; 147: 79-86.

Castro V, Murillo R, Klaas CA, Meunier C, Mora G, Pahl HL, Merfort I. Inhibition of the transcription factor NF-kappa B by sesquiterpene lactones from Podachaenium eminens. Planta Med. 2000; 66: 591-95.

Chen $\mathrm{CN}$, Huang $\mathrm{HH}$, Wu CL, Lin CP, Hsu JT, Hsieh HP, Chuang SE, Lai GM. Isocostunolide, a sesquiterpene lactone, induces mitochondrial membrane depolarization and caspase-dependent apoptosis in human melanoma cells. Cancer Lett. 2007; 246: 237-52.

Chen HC, Chou CK, Lee SD, Wang JC, Yeh SF. Active compounds from Saussurea lappa Clarks that suppress hepatitis B virus surface antigen gene expression in human hepatoma cells. Antiviral Res. 1995; 27: 99-109.

Choi JH, Ha J, Park JH, Lee JY, Lee YS, Park HJ, Choi JW, Masuda Y, Nakaya K, Lee KT. Costunolide triggers apoptosis in human leukemia U937 cells by depleting intracellular thiols. Jpn J Cancer Res. 2002a; 93: 1327-33.

Choi JH, Lee KT. Costunolide-induced apoptosis in human leukemia cells: Involvement of c-jun N-terminal kinase activation. Biol Pharm Bull. 2009; 32: 1803-08.

Choi JH, Seo BR, Seo SH, Lee KT, Park JH, Park HJ, Choi JW, Itoh Y, Miyamoto K. Costunolide induces differentiation of human leukemia HL-60 cells. Arch Pharm Res. 2002b; 25: 480 -84 .

Choi JY, Choi EH, Jung HW, Oh JS, Lee WH, Lee JG, Son JK, Kim Y, Lee SH. Melanogenesis inhibitory compounds from Saussureae radix. Arch Pharm Res. 2008; 31: 294-99.
Choi SH, Im E, Kang HK, Lee JH, Kwak HS, Bae YT, Park HJ , Kim ND. Inhibitory effects of costunolide on the telomerase activity in human breast carcinoma cells. Cancer Lett. 2005; 227: 153-62.

Choi YK, Seo HS, Choi HS, Kim SR, Shin YC, Ko SG. Induction of Fas-mediated extrinsic apoptosis, p21 WAF1-related G2/ $\mathrm{M}$ cell cycle arrest and ROS generation by costunolide in estrogen receptor-negative breast cancer cells, MDA-MB231. Mol Cell Biochem. 2011; 363: 119-28.

Corona D, Diaz E, Nava JL, Guzman A, Barrios H, Fuentes A, Hernandez-Plata SA, Allard J, Jankowski CK. (1)H, (13)C NMR and X-ray crystallographic studies of highly polyhalogenated derivatives of costunolide lactone. Spectrochim Acta A Mol Biomol Spectrosc. 2005; 62: 604-13.

Cragg GM, Newman DJ. Plants as a source of anti-cancer agents. J Ethnopharmacol. 2005; 100: 72-79.

De Marino S, Borbone N, Zollo F, Ianaro A, Di Meglio P, Iorizzi M. New sesquiterpene lactones from Laurus nobilis leaves as inhibitors of nitric oxide production. Planta Med. 2005; 71: 706-10.

el-Feraly FS, Chan YM. Isolation and characterization of the sesquiterpene lactones costunolide, parthenolide, costunolide diepoxide, santamarine, and reynosin from Magnolia grandiflora L. J Pharm Sci. 1978; 67: 347-50.

Ferlay J, Shin HR, Bray F, Forman D, Mathers C, Parkin DM. Estimates of worldwide burden of cancer in 2008: GLOBOCAN 2008. Int J Cancer 2010; 127: 2893-2917.

Ferrari B, Castilho P, Tomi F, Rodrigues AI, do Ceu Costa M, Casanova J. Direct identification and quantitative determination of costunolide and dehydrocostuslactone in the fixed oil of Laurus novocanariensis by 13C-NMR spectroscopy. Phytochem Anal. 2005; 16: 104-07.

Fischer NH, Lu T, Cantrell CL, Castaneda-Acosta J, Quijano L, Franzblau SG. Antimycobacterial evaluation of germacranolides. Phytochemistry 1998; 49: 559-64.

Fukuda K, Akao S, Ohno Y, Yamashita K, Fujiwara H. Inhibition by costunolide of phorbol ester-induced transcriptional activation of inducible nitric oxide synthase gene in a human monocyte cell line THP-1. Cancer Lett. 2001; 164: 713.

Furuya Y, Lundmo P, Short AD, Gill DL, Isaacs JT. The role of calcium, $\mathrm{pH}$, and cell proliferation in the programmed (apoptotic) death of androgen-independent prostatic cancer cells induced by thapsigargin. Cancer Res. 1994; 54: 6167-75.

Griffioen AW, Molema G. Angiogenesis: Potentials for pharmacologic intervention in the treatment of cancer, cardiovascular diseases, and chronic inflammation. Pharmacol Rev. 2000; 52: 237-68.

Harvey AL. Natural products in drug discovery. Drug Discov Today. 2008; 13: 894-901.

Hibasami H, Yamada Y, Moteki H, Katsuzaki H, Imai K, Yoshioka K, Komiya T. Sesquiterpenes (costunolide and zaluzanin D) isolated from laurel (Laurus nobilis L.) induce cell death and morphological change indicative of apoptotic chromatin condensation in leukemia HL-60 cells. Int J Mol Med. 2003; 12: 147-51. 
Hoeben A, Landuyt B, Highley MS, Wildiers H, Van Oosterom AT, De Bruijn EA. Vascular endothelial growth factor and angiogenesis. Pharmacol Rev. 2004; 56: 549-80.

Hsu JL, Pan SL, Ho YF, Hwang TL, Kung FL, Guh JH. Costunolide induces apoptosis through nuclear calcium2+ overload and DNA damage response in human prostate cancer. J Urol. 2011; 185: 1967-74.

Jeong SJ, Itokawa T, Shibuya M, Kuwano M, Ono M, Higuchi $\mathrm{R}$, Miyamoto T. Costunolide, a sesquiterpene lactone from Saussurea lappa, inhibits the VEGFR KDR/Flk-1 signaling pathway. Cancer Lett. 2002; 187: 129-33.

Kang JS, Yoon YD, Lee KH, Park SK, Kim HM. Costunolide inhibits interleukin-1beta expression by down-regulation of AP-1 and MAPK activity in LPS-stimulated RAW 264.7 cells. Biochem Biophys Res Commun. 2004; 313: 171-77.

Kanno S, Kitajima Y, Kakuta M, Osanai Y, Kurauchi K, Ujibe M, Ishikawa M. Costunolide-induced apoptosis is caused by receptor-mediated pathway and inhibition of telomerase activity in NALM-6 cells. Biol Pharm Bull. 2008; 31:1024-28.

Kassuya CA, Cremoneze A, Barros LF, Simas AS, Lapa Fda R, Mello-Silva R, Stefanello ME, Zampronio AR. Antipyretic and anti-inflammatory properties of the ethanolic extract, dichloromethane fraction and costunolide from Magnolia ovata (Magnoliaceae). J Ethnopharmacol. 2009; 124: 369-76.

Kawamori T, Tanaka T, Hara A, Yamahara J, Mori $\mathrm{H}$. Modifying effects of naturally occurring products on the development of colonic aberrant crypt foci induced by azoxymethane in F344 rats. Cancer Res. 1995; 55: 1277-82.

Kim JH, Yang YI, Lee KT, Park HJ, Choi JH. Costunolide induces apoptosis in human endometriotic cells through inhibition of the prosurvival Akt and nuclear factor kappa B signaling pathway. Biol Pharm Bull. 2011a; 34: 580-85.

Kim SH, Danilenko M, Kim TS. Differential enhancement of leukaemia cell differentiation without elevation of intracellular calcium by plant-derived sesquiterpene lactone compounds. Br J Pharmacol. 2008; 155: 814-25.

Kim SH, Kang SN, Kim HJ, Kim TS. Potentiation of 1,25dihydroxyvitamin $\mathrm{D}(3)$-induced differentiation of human promyelocytic leukemia cells into monocytes by costunolide, a germacranolide sesquiterpene lactone. Biochem Pharmacol. 2002; 64: 1233-42.

Kim TJ, Nam KW, Kim B, Lee SJ, Oh KB, Kim KH, Mar W, Shin J. Inhibitory Effects of costunolide Isolated from Laurus nobilis on IgE-induced degranulation of mast cell-like RBL$2 \mathrm{H} 3$ cells and the growth of Y16 pro-B Cells. Phytother Res. 2011b; 25: 1392-97.

Ko SG, Kim HP, Jin DH, Bae HS, Kim SH, Park CH, Lee JW. Saussurea lappa induces G2-growth arrest and apoptosis in AGS gastric cancer cells. Cancer Lett. 2005; 220: 11-19.

Komiya T, Yamada Y, Moteki H, Katsuzaki H, Imai K, Hibasami H. Hot water soluble sesquiterpenes [anhydroperoxy-costunolide and 3-oxoeudesma-1,4(15),11 (13)triene-12,6alpha-olide] isolated from laurel (Laurus nobilis L.) induce cell death and morphological change indicative of apoptotic chromatin condensation in leukemia cells. Oncol Rep. 2004; 11: 85-88.
Koo TH, Lee JH, Park YJ, Hong YS, Kim HS, Kim KW, Lee JJ. A sesquiterpene lactone, costunolide, from Magnolia grandiflora inhibits NF-kappa B by targeting I kappa B phosphorylation. Planta Med. 2001; 67: 103-07.

Kroemer G, Petit P, Zamzami N, Vayssiere JL, Mignotte B. The biochemistry of programmed cell death. FASEB J. 1995; 9: 1277-87.

Lee MG, Lee KT, Chi SG, Park JH. Costunolide induces apoptosis by ROS-mediated mitochondrial permeability transition and cytochrome C release. Biol Pharm Bull. 2001; 24: 303-06.

Li A, Sun A, Liu R. Preparative isolation and purification of costunolide and dehydrocostuslactone from Aucklandia lappa Decne by high-speed counter-current chromatography. J Chromatogr A. 2005; 1076: 193-97.

Li S, An TY, Li J, Shen Q, Lou FC, Hu LH. PTP1B inhibitors from Saussrurea lappa. J Asian Nat Prod Res. 2006; 8: 281-86.

Liekens S, De Clercq E, Neyts J. Angiogenesis: Regulators and clinical applications. Biochem Pharmacol. 2001; 61: 253-70.

Liu CY, Chang HS, Chen IS, Chen CJ, Hsu ML, Fu SL, Chen YJ. Costunolide causes mitotic arrest and enhances radiosensitivity in human hepatocellular carcinoma cells. Radiat Oncol. 2011a; 6: 56.

Liu ZL, He Q, Chu SS, Wang CF, Du SS, Deng ZW. Essential oil composition and larvicidal activity of Saussurea lappa roots against the mosquito Aedes albopictus (Diptera: Culicidae). Parasitol Res. 2011b; DOI: 10.1007/s00436-0112738-0.

Luna-Herrera J, Costa MC, Gonzalez HG, Rodrigues AI, Castilho PC. Synergistic antimycobacterial activities of sesquiterpene lactones from Laurus spp. J Antimicrob Chemother. 2007; 59: 548-52.

Macias FA, Galindo JC, Castellano D, Velasco RF. Sesquiterpene lactones with potential use as natural herbicide models (I): trans,trans-germacranolides. J Agric Food Chem. 1999; 47: 4407-14.

Mata R, Rivero-Cruz I, Rivero-Cruz B, Bye R, Timmermann $\mathrm{BN}$. Sesquiterpene lactones and phenylpropanoids from Cosmos pringlei. J Nat Prod. 2002; 65: 1030-32.

Matsuda H, Kagerura T, Toguchida I, Ueda H, Morikawa T, Yoshikawa M. Inhibitory effects of sesquiterpenes from bay leaf on nitric oxide production in lipopolysaccharideactivated macrophages: Structure requirement and role of heat shock protein induction. Life Sci. 2000; 66: 2151-57.

Matsuda H, Shimoda H, Ninomiya $K$, Yoshikawa $M$. Inhibitory mechanism of costunolide, a sesquiterpene lactone isolated from Laurus nobilis, on blood-ethanol elevation in rats: Involvement of inhibition of gastric emptying and increase in gastric juice secretion. Alcohol Alcohol. 2002; 37: 121-27.

Mondranondra IO, Che CT, Rimando AM, Vajrodaya S, Fong $\mathrm{HH}$, Farnsworth NR. Sesquiterpene lactones and other constituents from a cytotoxic extract of Michelia floribunda. Pharm Res. 1990; 7: 1269-72.

Mori H, Kawamori T, Tanaka T, Ohnishi M, Yamahara J. Chemopreventive effect of costunolide, a constituent of 
oriental medicine, on azoxymethane-induced intestinal carcinogenesis in rats. Cancer Lett. 1994; 83: 171-75.

Nam NH. Naturally occurring NF-kappa B inhibitors. Mini Rev Med Chem. 2006; 6: 945-51.

Newman DJ, Cragg GM. Natural products as sources of new drugs over the last 25 years. J Nat Prod. 2007; 70: 461-77.

Pae HO, Jeong GS, Kim HS, Woo WH, Rhew HY, Sohn DH, Kim YC, Chung HT. Costunolide inhibits production of tumor necrosis factor-alpha and interleukin- 6 by inducing heme oxygenase-1 in RAW264.7 macrophages. Inflamm Res. 2007; 56: 520-26.

Pandey MM, Rastogi S, Rawat AK. Saussurea costus: Botanical, chemical and pharmacological review of an ayurvedic medicinal plant. J Ethnopharmacol. 2007; 110: 379-90.

Park HJ, Jung WT, Basnet P, Kadota S, Namba T. Syringin 4-Obeta-glucoside, a new phenylpropanoid glycoside, and costunolide, a nitric oxide synthase inhibitor, from the stem bark of Magnolia sieboldii. J Nat Prod. 1996; 59: 1128-30.

Park HJ, Kwon SH, Han YN, Choi JW, Miyamoto K, Lee SH, Lee KT. Apoptosis-Inducing costunolide and a novel acyclic monoterpene from the stem bark of Magnolia sieboldii. Arch Pharm Res. 2001a; 24: 342-48.

Park HW, Lee JH, Choi SU, Baek NI, Kim SH, Yang JH, Kim DK. Cytotoxic germacranolide sesquiterpenes from the bark of Magnolia kobus. Arch Pharm Res. 2010; 33: 71-74.

Park SH, Choi SU, Lee CO, Yoo SE, Yoon SK, Kim YK, Ryu SY. Costunolide, a sesquiterpene from the stem bark of Magnolia sieboldii, inhibits the RAS-farnesyl-proteintransferase. Planta Med. 2001b; 67: 358-59.

Rasul A, Yu B, Yang L, Arshad M, Khan M, Ma T, Yang H. Costunolide, a sesquiterpene lactone, induces G2/M phase arrest and mitochondria-mediated apoptosis in human gastric adenocarcinoma SGC-7901 cells. J Med Plants Res. 2011; 6: 1191-1200.

Song XK, Tu PF, Wu LJ, Cai Y, Zhu H, Lu Y, Liu XY, Zheng QT. A new sesquiterpene lactone from Tsoongiodendron odorum Chun. J Asian Nat Prod Res. 2001; 3: 285-91.

Srivastava SK, Abraham A, Bhat B, Jaggi M, Singh AT, Sanna
VK, Singh G, Agarwal SK, Mukherjee R, Burman AC. Synthesis of 13-amino costunolide derivatives as anti-cancer agents. Bioorg Med Chem Lett. 2006; 16: 4195-99.

Stefani R, Schorr K, Tureta JM, Vichnewski W, Merfort I, da Costa FB. Sesquiterpene lactones from Dimerostemma species (Asteraceae) and in vitro potential anti-inflammatory activities. Z Naturforsch C. 2006; 61: 647-52.

Sun CM, Syu WJ, Don MJ, Lu JJ, Lee GH. Cytotoxic sesquiterpene lactones from the root of Saussurea lappa. J Nat Prod. 2003; 66: 1175-80.

Taylor WR, Stark GR. Regulation of the G2/M transition by p53. Oncogene 2001; 20: 1803-15.

Wedge DE, Galindo JC, Macias FA. Fungicidal activity of natural and synthetic sesquiterpene lactone analogs. Phytochemistry 2000; 53: 747-57.

Woynarowski JM, Napier C, Koester SK, Chen SF, Troyer D, Chapman W, MacDonald JR. Effects on DNA integrity and apoptosis induction by a novel antitumor sesquiterpene drug, 6-hydroxymethylacylfulvene (HMAF, MGI 114). Biochem Pharmacol. 1997; 54: 1181-93.

Wu SH, Luo XD, Ma YB, Hao XJ, Zhou J, Wu DG. Two new germacranolides from Magnolia grandiflora. J Asian Nat Prod Res. 2001; 3: 95-102.

Yang NY, Duan JA, Shang EX, Tian LJ. Analysis of sesquiterpene lactones in Eupatorium lindleyanum by HPLCPDA-ESI-MS/MS. Phytochem Anal. 2010; 21: 144-49.

Yang YI, Kim JH, Lee KT, Choi JH. Costunolide induces apoptosis in platinum-resistant human ovarian cancer cells by generating reactive oxygen species. Gynecol Oncol. 2011; 123: 588-96.

Zhang Q, Cai D, Liu J. Matrix solid-phase dispersion extraction coupled with HPLC-diode array detection method for the analysis of sesquiterpene lactones in root of Saussurea lappa C.B. Clarke. J Chromatogr B Analyt Technol Biomed Life Sci. 2011; 879: 2809-14.

Zhang S, Won YK, Ong CN, Shen HM. Anti-cancer potential of sesquiterpene lactones: Bioactivity and molecular mechanisms. Curr Med Chem Anti-cancer Agents. 2005; 5: $239-49$.

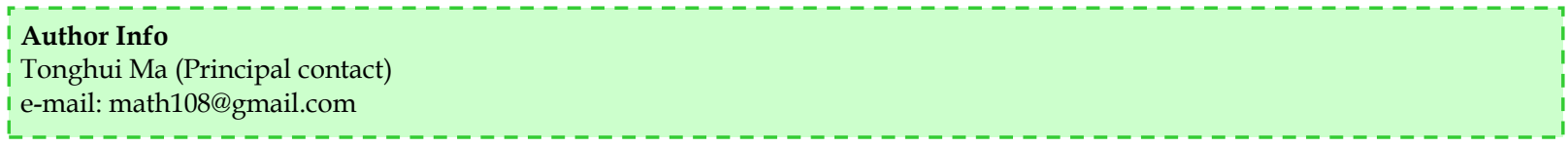

